\title{
Pengaruh Suhu Annealing terhadap Struktur Mikro dan Sifat Optik Lapisan Bismuth Ferrite $\left(\mathrm{BiFeO}_{3}\right)$
}

\author{
Yofentina Iriani, Novinda Hary Megasari, dan Fahru Nurosyid \\ Program Studi Fisika, Fakultas MIPA, Universitas Sebelas Maret, Surakarta \\ yofent_iriani@staff.uns.ac.id
}

\section{ABSTRACT}

This study aims to determine the effect of annealing temperature on the microstructure and optical properties of Bismuth Ferrite $\left(\mathrm{BiFeO}_{3}\right)$ layers. $\mathrm{BiFeO}_{3}$ film was successfully deposited on a quartz substrate using the Chemical Solution Deposition (CSD) method. The microstructure was characterized by XRD and optical properties was characterized with UV-Vis spectrophotometer. The annealing temperature variations are $550^{\circ} \mathrm{C}, 600^{\circ} \mathrm{C}$, and $650^{\circ} \mathrm{C}$. Annealing temperature affect the microstructure i.e., crystallite size, crystallinity, lattice parameters and optical properties i.e., absorbance and energy gap. The crystallite size, crystallinity, and lattice parameters increase with increased annealing temperature. The peak of absorbance has decreased with the increase in annealing temperature. The lowest energy gap is at $650^{\circ} \mathrm{C}$ annealing temperature which is $(2,45 \pm 0,02) \mathrm{eV}$.

Keywords : $\mathrm{BiFeO}_{3}$, annealing, microstructure, optical properties, CSD.

\section{ABSTRAK}

Penelitian ini bertujuan untuk mengetahui pengaruh suhu annealing terhadap struktur mikro dan sifat optik lapisan Bismuth Ferrite $\left(\mathrm{BiFeO}_{3}\right)$. Lapisan $\mathrm{BiFeO}_{3}$ telah berhasil berhasil terdeposisi di atas substrat quartz menggunakan metode Chemical Solution Deposition (CSD). Struktur mikro dikarakterisasi menggunakan XRD dan sifat optik dikarakterisasi menggunakan spektrofotometer UV-Vis. Variasi suhu annealing yang dilakukan yaitu $550^{\circ} \mathrm{C}, 600^{\circ} \mathrm{C}$, dan $650^{\circ} \mathrm{C}$. Suhu annealing mempengaruhi struktur mikro yaitu ukuran kristal, tingkat kekristalan, parameter kisi serta mempengaruhi sifat optik yaitu absorbansi dan energi gap lapisan $\mathrm{BiFeO}_{3}$. Semakin tinggi suhu annealing maka ukuran kristal, tingkat kekristalan, dan parameter kisi meningkat. Puncak absorbansi mengalami penurunan seiring dengan bertambahnya suhu annealing. Suhu annealing mempengaruhi energi gap lapisan $\mathrm{BiFeO}_{3}$. Energi gap paling rendah yaitu pada suhu annealing $650^{\circ} \mathrm{C}$ sebesar $(2,45 \pm 0,02) \mathrm{eV}$.

Kata Kunci : $\mathrm{BiFeO}_{3}$, annealing, struktur mikro, sifat optik, CSD.

\section{PENDAHULUAN}

Material ferroelektrik merupakan material yang memiliki polarisasi spontan dengan adanya pengaruh medan listrik luar, ini dapat dilihat dari kurva histerisis yang terbentuk. Kurva histerisis merupakan kurva hubungan polarisasi $(P)$ terhadap medan listrik luar $(E)$. Material ferroelektrik mengalami fase transisi struktur pada Temperature Curie $\left(T_{C}\right)$ yaitu perubahan fase dari fase ferroelektrik menjadi fase paraelektrik ${ }^{[1]}$. $\mathrm{BiFeO}_{3}$ adalah salah satu material ferroelektrik yang berstruktur perovskite memiliki sifat optik menarik dalam photovoltaic yaitu memiliki energi gap yang sempit ${ }^{[2]}$. Photovoltaic adalah teknologi yang memanfaatkan energi sinar matahari sebagai energi alternatif. Photovoltaic mengubah energi cahaya menjadi energi listrik, biasanya menggunakan bahan semikonduktor ${ }^{[3]}$. Lapisan $\mathrm{BiFeO}_{3}$ biasanya dibuat dengan metode Chemical Solution Deposition (CSD $)^{[4]}$. Metode CSD banyak digunakan karena memiliki beberapa keunggulan, diantaranya kemampuan kontrol komposisi dan homogenitas yang baik. Struktur mikro dan sifat optik dari $\mathrm{BiFeO}_{3}$ dapat dipengaruhi oleh parameter pengolahannya. Salah satu parameter pengolahannya adalah suhu annealing ${ }^{[5]}$. 
Pembuatan lapisan menggunakan metode CSD melibatkan sintesis larutan prekursor, deposisi lapisan menggunakan spin-coating atau dip-coating, proses pengeringan dilakukan pada perlakuan panas suhu rendah, dan perlakuan panas suhu lebih tinggi dilakukan untuk densifikasi dan kristalisasi lapisan ${ }^{[6]}$. Spin coating merupakan teknik pembentukan lapisan melalui proses pemutaran atau spin. Bahan yang akan dibentuk lapisan dibuat dalam bentuk larutan atau gel, kemudian diteteskan pada substrat yang diletakkan di atas piringan lalu diputar dengan kecepatan tertentu ${ }^{[7]}$. Paper ini akan membahas pengaruh suhu annealing terhadap struktur mikro dan sifat optik lapisan.

\section{METODE}

Pembuatan lapisan $\mathrm{BiFeO}_{3}$ dilakukan menggunakan metode Chemical Solution Deposition (CSD) yang disiapkan dengan spin coater. Bahan-bahan penyusun Bismuth Ferrite $\left(\mathrm{BiFeO}_{3}\right)$ yang digunakan adalah bismuth nitrate pentahydrate $\left(\mathrm{Bi}\left(\mathrm{NO}_{3}\right)_{3} .5 \mathrm{H}_{2} \mathrm{O}\right)(\mathrm{Kojundo}, 99.99 \%)$, iron nitrate enneahydrate $\left(\mathrm{Fe}\left(\mathrm{NO}_{3}\right)_{3} .9 \mathrm{H}_{2} \mathrm{O}\right)$ (Kojundo, 99.9\%), acetic acid $\left(\mathrm{CH}_{3} \mathrm{COOH}\right)$ (Sigma Aldrich, $\geq 99.7 \%$ ), 2-methoxyetanol $\left(\mathrm{CH}_{3} \mathrm{OCH}_{2} \mathrm{CH}_{2} \mathrm{OH}\right)$ (Sigma Aldrich, $\geq 99.8 \%$ ), dan acetylacetone $\left(\mathrm{CH}_{3} \mathrm{COCH}_{2} \mathrm{COCH}_{3}\right)$ (Sigma Aldrich, $\left.\geq 99.3 \%\right)$. Substrat yang digunakan adalah quartz. Tahapan metode CSD meliputi proses sintesis larutan, proses deposisi, proses hidrolisis, dan proses annealing. Larutan dibuat dengan volume $5 \mathrm{ml}$ dan molaritas $1 \mathrm{M}$. Urutan pencampuran bahannya antara lain bismuth nitrate pentahydrate dan iron nitrate enneahydrate ditambah dengan aceticacid dan 2-methoxyetanol kemudian diaduk menggunakan magnetic stirer selama 60 menit. Acetylacetone (penyetabil) ditambahkan ke dalam pencampuran sebelumnya kemudian diaduk menggunakan magnetic stirer selama 45 menit. Variasi suhu annealing yang dilakukan adalah $550^{\circ} \mathrm{C}, 600^{\circ} \mathrm{C}$, dan $650^{\circ} \mathrm{C}$ dengan waktu tahan selama 1 jam. Pengaruh suhu annealing pada struktur mikro lapisan $\mathrm{BiFeO}_{3}$ diuji menggunakan X-Ray Diffraction (XRD) Bruker D8 Advance dengan anoda Cu. Data hasil pengujian ini berupa sudut difraksi (2Ө) dan intensitas. Data hasil XRD kemudian digunakan untuk menghitung ukuran kristal $(D)$ menggunakan persamaan Scherrer sebagai berikut ${ }^{[8]}$ :

$$
D=\frac{0,9 \lambda}{\beta \cos \theta}
$$

dimana $D$ adalah ukuran kristal $(\mathrm{nm}), \lambda$ adalah panjang gelombang sinar-X (1,5406 $\AA$ ), $\beta$ adalah FWHM (full width at half maximum) (rad), dan $\theta$ adalah sudut difraksi pada Hukum Bragg.

Spektrofotometer UV-Vis digunakan untuk mengukur besar absorbansi dan transmitansi suatu material serta mengukur energi gap antara pita konduksi dan pita valensi. Penentuan energi gap menggunakan metode Tauc-Plot yaitu dengan cara menarik garis linear dari grafik hubungan $(\alpha h v)^{2}$ terhadap hv hingga memotong sumbu x. Persamaan Tauc-Plot dapat ditulis sebagai berikut ${ }^{[9]}$ :

$$
(\alpha h v)^{2}=C\left(h v-E_{g}\right)
$$

$\alpha$ adalah koefisien absorbansi $\left(\mathrm{m}^{-1}\right), h$ adalah konstanta planck, $v$ adalah frekuensi gelombang $(\mathrm{Hz}), \mathrm{C}$ adalah konstanta, dan $E_{g}$ adalah energi gap $(\mathrm{eV})$.

\section{HASIL DAN PEMBAHASAN}

Lapisan Bismuth Ferrite $\left(\mathrm{BiFeO}_{3}\right)$ dikarakterisasi menggunakan X-Ray Diffraction (XRD) untuk mengetahui struktur mikro dari lapisan. Struktur mikro lapisan $\mathrm{BiFeO}_{3}$ yang dihitung adalah ukuran kristal, tingkat kekristalan dan parameter kisi. Hasil karakterisasi menggunakan XRD berupa pola difraksi hubungan antara sudut difraksi $(2 \theta)$ dengan intensitas. 


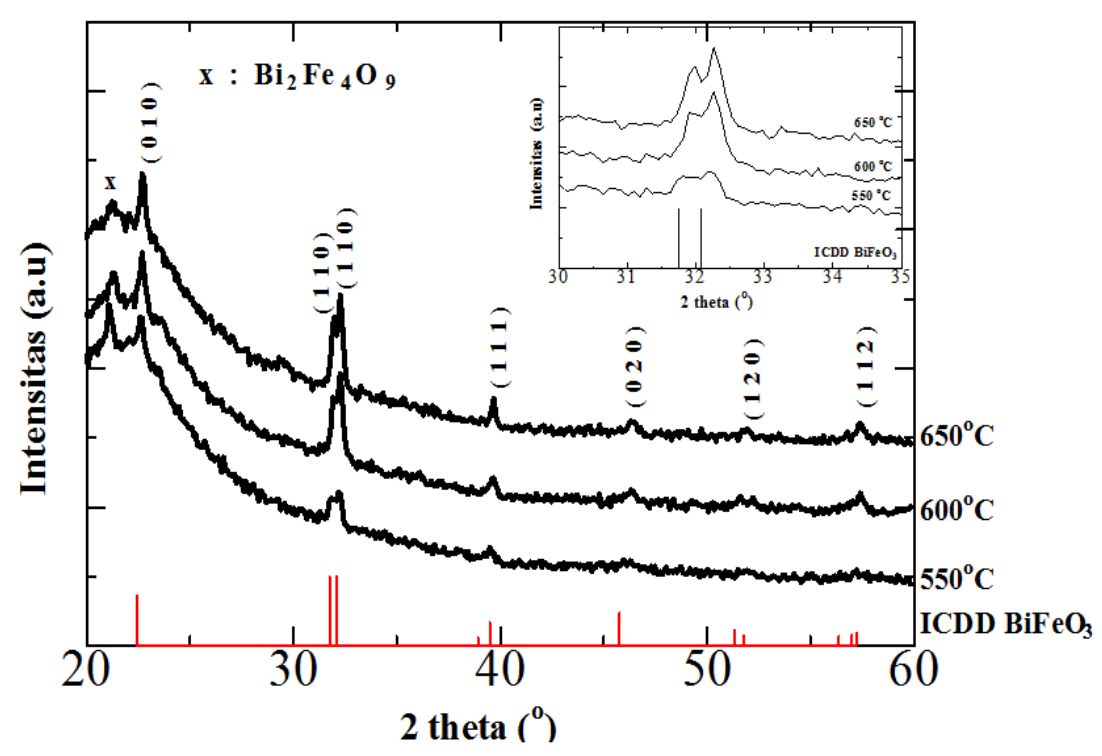

Gambar 1. Pola difraksi lapisan $\mathrm{BiFeO}_{3}$ variasi suhu annealing

Gambar 1 adalah pola difraksi lapisan $\mathrm{BiFeO}_{3}$ dengan variasi suhu annealing. Terlihat bahwa $\mathrm{BiFeO}_{3}$ di atas substrat quartz. Hal ini ditandai dengan munculnya puncak-puncak difraksi teridentifikasi milik $\mathrm{BiFeO}_{3}$ setelah dicocokkan dengan ICDD database (ICDD \#742016).

Tabel 1 adalah intensitas, tingkat kekristalan dan ukuran kristal lapisan $\mathrm{BiFeO}_{3}$ untuk variasi suhu annealing. Terlihat bahwa semakin tinggi suhu annealing maka intensitas, tingkat keristalan dan ukuran kristal lapisan $\mathrm{BiFeO}_{3}$ juga semakin tinggi. Hal ini disebabkan karena makin tinggi suhu maka makin banyak atom-atom yang bervibrasi sehingga atom-atom menjadi teratur.

Tabel 1. Intensitas, tingkat kekristalan dan ukuran kristal lapisan $\mathrm{BiFeO}_{3}$ variasi suhu annealing

\begin{tabular}{cccc}
\hline Suhu Annealing & $\begin{array}{c}\text { Intensitas } \\
\text { orientasi }(110)\end{array}$ & $\begin{array}{c}\text { Tingkat kekristalan } \\
(\%)\end{array}$ & $\begin{array}{c}\text { Ukuran Kristal } \\
(\mathrm{nm})\end{array}$ \\
\hline $550^{\circ} \mathrm{C}$ & 2212 & 76 & 14 \\
$600^{\circ} \mathrm{C}$ & 2922 & 86 & 29 \\
$650^{\circ} \mathrm{C}$ & 3057 & 88 & 33 \\
\hline
\end{tabular}

Ketebalan lapisan $\mathrm{BiFeO}_{3}$ diukur menggunakan Dektak Profilometer yang dapat dilihat pada Tabel 2. Berdasarkan Tabel 2 terlihat bahwa semakin tinggi suhu annealing ketebalan lapisan semakin rendah.

Tabel 2. Ketebalan Lapisan $\mathrm{BiFeO}_{3}$ variasi suhu annealing

\begin{tabular}{cc}
\hline Suhu Annealing & Ketebalan $(\mathrm{nm})$ \\
\hline $550^{\circ} \mathrm{C}$ & 268 \\
$600^{\circ} \mathrm{C}$ & 151 \\
$650^{\circ} \mathrm{C}$ & 82 \\
\hline
\end{tabular}




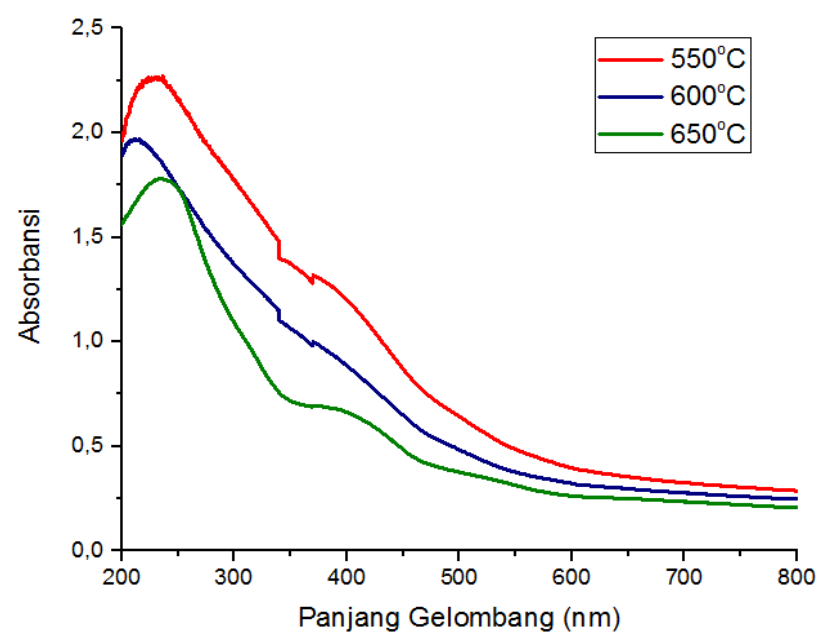

Gambar 2. Grafik hubungan antara panjang gelombang dan absorbansi variasi suhu annealing

Karakterisasi menggunakan spektrofotometer UV-Vis dilakukan untuk mengetahui sifat optik lapisan $\mathrm{BiFeO}_{3}$. Hasil karakterisasi menggunakan spektrofotometer UV-Vis berupa data absorbansi dan transmitansi. Nilai absorbansi menunjukkan besarnya serapan lapisan $\mathrm{BiFeO}_{3}$ dan nilai transmitansi digunakan dalam perhitungan nilai band gap. Hasil absorbansi ditunjukkan pada Gambar 2.

Berdasarkan Gambar 2. terlihat bahwa peningkatan suhu annealing menyebabkan puncak absorbansi mengalami penurunan. Puncak absorbansi tertinggi yaitu pada saat suhu annealing $550^{\circ} \mathrm{C}$. Puncak absorbansi terdapat pada daerah UV yaitu range panjang gelombang (200-400) nm.

Tabel 3. Energi gap lapisan $\mathrm{BiFeO}_{3}$ variasi suhu annealing

\begin{tabular}{cc}
\hline Suhu Annealing & Energi Gap (eV) \\
\hline $550^{\circ} \mathrm{C}$ & $(2,80 \pm 0,04)$ \\
$600^{\circ} \mathrm{C}$ & $(2,68 \pm 0,03)$ \\
$650^{\circ} \mathrm{C}$ & $(2,45 \pm 0,02)$ \\
\hline
\end{tabular}



Gambar 3. Energi gap $\mathrm{BiFeO}_{3}$ variasi suhu anneling 
Sifat optik lapisan $\mathrm{BiFeO}_{3}$ tidak hanya terlihat dari nilai absorbansi, tetapi juga terlihat dari nilai energi gap-nya. Nilai energi gap dihitung menggunakan Persamaan 2. Hasil perhitungan energi gap seperti yang terlihat pada Gambar 3. Grafik energi gap merupakan grafik hubungan $(\alpha h v)^{2}$ terhadap $h v$. Besarnya energi gap diperoleh dari perpanjangan garis lurus dari grafik yang terbentuk sehingga memotong sumbu x. Dari Tabel 3 dan Gambar 3 terlihat bahwa besarnya energi gap dipengaruhi oleh suhu annealing. Energi gap paling rendah terdapat pada suhu annealing $650^{\circ} \mathrm{C}$ yaitu sebesar $(2,45 \pm 0,02) \mathrm{eV}$. Hal ini sesuai dengan penelitian $\mathrm{Xu}$ and Shen (2008) yaitu energi gap yang lebih rendah disebabkan karena peningkatan tingkat kristalinitas dan homogenitas dari lapisan $\mathrm{BiFeO}_{3}{ }^{[5]}$.

\section{KESIMPULAN}

Lapisan $\mathrm{BiFeO}_{3}$ telah terdoposisi di atas substrat quartz. Suhu annealing mempengaruhi struktur mikro yaitu ukuran kristal, tingkat kekristalan, parameter kisi serta mempengaruhi sifat optik yaitu absorbansi dan energi gap lapisan $\mathrm{BiFeO}_{3}$. Semakin tinggi suhu annealing maka ukuran kristal, tingkat kekristalan, dan parameter kisi meningkat. Puncak absorbansi mengalami penurunan seiring dengan bertambahnya suhu annealing. Suhu annealing mempengaruhi energi gap lapisan $\mathrm{BiFeO}_{3}$. Energi gap paling rendah yaitu pada suhu annealing $650^{\circ} \mathrm{C}$ sebesar $(2,45 \pm 0,02) \mathrm{eV}$.

\section{UCAPAN TERIMAKASIH}

Penulis mengucapkan terimakasih Universitas Sebelas Maret melalui penelitian skema Hibah Penelitian Unggulan UNS Dana PNBP Tahun Anggaran 2019, dengan nomor kontrak : 516/UN27.21/PP/2019

\section{DAFTAR PUSTAKA}

1 Wang, Y., Chen, W., Wang, B., \& Zheng, Y. 2014. Ultrathin Ferroelectric Films : Growth Characterization, Physics, and Applications. Materials, 7, 6377-6485.

2 Xue, X., Tan, G., Liu, W., \& Hao, H. 2014. Structural, optical and magnetic properties of BiFe1-xCoxO3 thin films. Materials Letters, 128, 303-305.

3 Tang, X., Jin, L., Dai, J., Zhu, X., \& Sun, Y. 2016. Decreased oxygen vacancies and improved ferroelectric properties of the $\mathrm{BiFeO}_{3}$ thin films with high magnetic field annealing. Journal of Alloy and Compound, 30, 1-6.

4 Sharma, S., Tomar, M., Kumar, A., Puri, N. K., \& Gupta, V. 2016. Photovoltaic effect in $\mathrm{BiFeO}_{3} / \mathrm{BaTiO}_{3}$ multilayer structure fabricated by chamical solution deposition technique. Journal of Physics and Chemistry of Solids, 93, 63-67.

$5 \mathrm{Xu}, \mathrm{Y} . \&$ Shen, M. 2008. Structure and optical properties of nanocrystalline BiFeO3 films prepared by Chemical Solution Deposition. Materials Letters, 62, 3600-3602.

6 Shima, H., Naganuma, H., \& Okamura, S. 2013. Optical properties of multiferroic BiFeO3 films. Material Science - Advance Topics, ISBN : 978-953-51-1140-5, Publisher : InTech.

7 Hidayat, A. S., Rokhmat, M., \& Qurthobi, A.2014. Pengaruh Suhu Dan Kecepatan Putar Spin Coating Terhadap Kinerja Sel Surya Organik Berbahan Dasar Tio2. Jurnal Eprac, (1), 1-14.

8 Shirahata, Y. \& Oku, T. 2016. Characterization and Photovoltaic Properties of $\mathrm{BiFeO}_{3}$ Thin Films. Coatings, 6, 68.

9 Bao, D., Yang, H., Zhang, L., \& Yao, X. 1998. Structure and Optical Properties of SrTiO3 Thin Films Prepared by a Sol-Gel Technique. Phys. Stat. sol.,169, 227-233. 